patología de base que llevó al estudio histológico y a su diagnóstico. En resumen, hemos presentado un nuevo caso de NAP, descubierto incidentalmente en el estudio anatomopatológico de una pieza de adenomectomía prostática con una hiperplasia benigna de próstata y hemos discutido los principales diagnósticos diferenciales anatomopatológicos, entre los que destaca el diagnóstico diferencial con el melanoma maligno primario o secundario.

B I B L I O G R A F Í A

1. Kerl H, LeBoit PE, Bastian BC. Pathology and genetics of skin tumors. En: LeBoit PH, Weedon D, Sarasin A, editors. WHO. Lyon: IARC Press; 2006. p. 95.

2. González-Campora R, Galera-Davidson H, Vazquez-Ramírez FJ, Díaz-Cano S. Blue Nevus: Classical types and new related entities. A differential diagnostic review. Pathol Res Pract. 1994;190:627-35.

3. Cuervo Pinna C, Godoy Rubio E, Parra Escobar JL, Sánchez Blasco E, Valverde Valverde J, Moreno Casado J. Nevus azul prostático. Estandarización de la terminología de las lesiones pigmentadas de la próstata. Actas Urol Esp. 2001;25:245-7.

4. Klock C, Gomes R, Joao M, Netto G. Prostate melanosis associated with acinar adenocarcinoma. Int J Surg Pathol. 2008.
5. Redondo Martínez E, Rey López A, Díaz Cascajo C. Nevus azul de la próstata. Diagnóstico diferencial de las lesiones pigmentadas prostáticas. Arch Esp Urol. 1998;51:286-9.

6. Vesga Molina F, Acha Pérez M, Llarena Ibarguren R, Pertusa Pena C. Nevus azul intraprostático. Arch Esp Urol. 1995;48: 985-6.

7. Wang CJ, Chen YT, Shun CT, Lai MK. Primary malignant melanoma of the prostate. J Urol. 1995;154:1865.

8. Wong J, Wise GJ, Clark B. Malignant melanoma of the prostate: A case report. Can J Urol. 2008;15:4027-9.

9. Wang CJ. Followup of primary malignant melanoma of the prostate. J Urol. 2001;166:214.

\section{J. Marti-Mestre ${ }^{\mathrm{a}}$, D. Cañis-Sánchez ${ }^{\mathrm{a}}$, J.-M. Jaén-Martínez ${ }^{\mathrm{b}}$ y R. Bosch Princep ${ }^{\mathrm{b}, *}$}

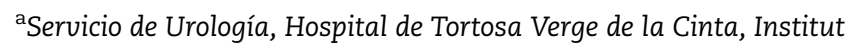
d'Investigació Sanitaria Pere Virgili, Tortosa, Tarragona, España ${ }^{\mathrm{b}}$ Servicio de Anatomía Patológica, Hospital de Tortosa Verge de la Cinta, Institut d'Investigació Sanitaria Pere Virgili, Tortosa, Tarragona, España

*Autor para correspondencia.

Correo electrónico: rbosch.ebre.ics@gencat.cat

(R. Bosch Princep).

\title{
Seminoma clásico testicular que inicia como abdomen agudo. A propósito de un caso
}

\section{Classic testicular seminoma that initiates as acute abdomen. A case report}

\section{Sr. Director:}

La semiología del tumor testicular ya está descrita de forma extensa en la literatura médica, y en la mayor parte de los pacientes se circunscribe al escroto. El caso que nos atañe presenta una forma atípica de inicio, por lo que creemos que su lectura puede resultar de interés y constituye un ejemplo más de que la exploración física completa es crucial en la evaluación de un paciente.

Acude a nuestro servicio de Urgencias un varón de 39 años, procedente del este de Europa, sin antecedentes de interés. Refiere dolor tipo cólico transfixiante de predominio en el hemiabdomen inferior, en la fosa ilíaca izquierda, que ha sido refractario a analgésicos habituales. Niega traumatismo previo u otra sintomatología urológica.

A la exploración física, presenta una masa en el vacío-fosa ilíaca izquierda, dolorosa a la palpación. El teste derecho es normal, se palpan dos nódulos de consistencia pétrea en el teste izquierdo.

En el hemograma se observa una discreta leucocitosis (10.900 L/Mcl), con una neutrofilia del 90,7\%, una linfopenia de
6.300 Leucocitos/Mcl y una trombocitosis de 464.000; la bioquímica no presenta alteraciones reseñables y en la gasometría se observa una alcalosis respiratoria con un $\mathrm{pH}$ de 7,62. A la vista de estos hallazgos, se realiza un estudio ecográfico abdominal, en el que se visualiza una imagen compatible con un conglomerado adenopático retroperitoneal precavoaórtico de aproximadamente $11 \times 6 \mathrm{~cm}$, siendo el nódulo mayor paraaórtico de $6 \times 5 \mathrm{~cm}$. En el lóbulo hepático derecho se observa una lesión focal sólida hipoecogénica de $8 \mathrm{~mm}$. La ecografía escrotal muestra el teste derecho normal $\mathrm{y}$, en el izquierdo, microlitiasis y dos nódulos hipoecoicos de 14,3 y de $8,5 \mathrm{~mm}$, y la presencia de una masa de $4 \mathrm{~cm}$.

Se somete al paciente a orquiectomía radical izquierda, sin incidencias. El diagnóstico anatomopatológico es el siguiente: seminoma clásico con intensa reacción sarcoidea y extensión a las cubiertas testiculares, al epidídimo y a la parte proximal del cordón (fig. 1); áreas de Cis; lesiones esclerosadas compatibles con áreas de tumor quemado y vasculitis granulomatosa de vasos del epidídimo e intratumorales (seminoma clásico pT3).

La TC descarta la existencia de enfermedad nodular torácica y de lesiones en el parénquima pulmonar. El hígado, 


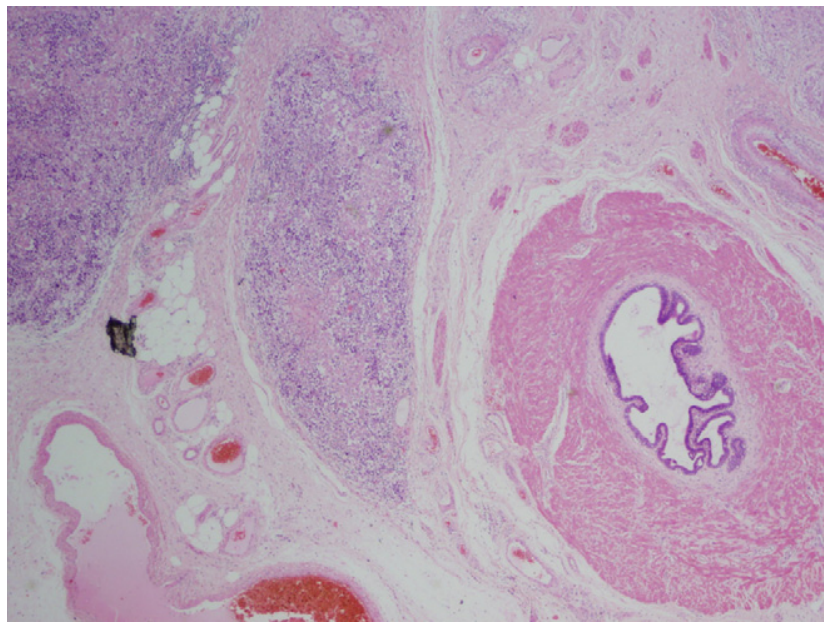

Figura 1 - Corte histológico del cordón espermático con nidos tumorales entre las estructuras vasculares (HE $20 \times$ ).

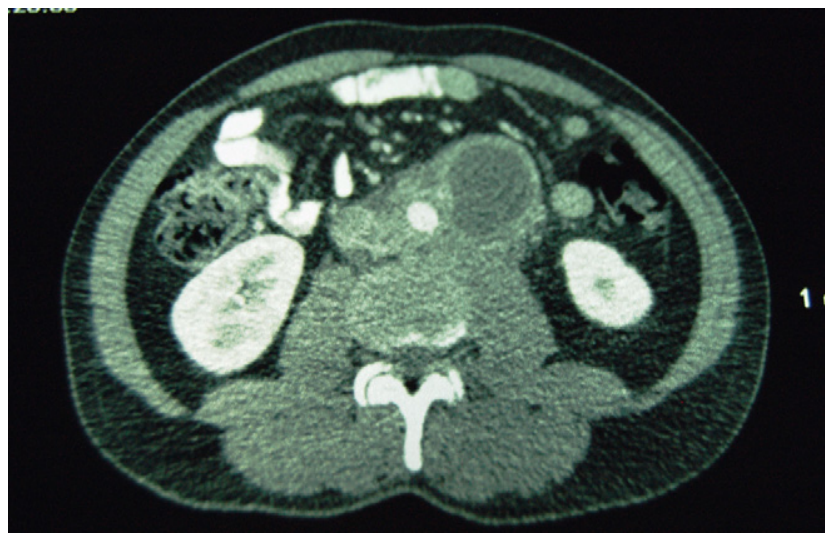

Figura 2 - Corte tomográfico del conglomerado adenopático que muestra zonas de necrosis quística.

la vía biliar, el bazo, el páncreas, las adrenales y los riñones no presentan alteraciones. Importante conglomerado adenopático retroperitoneal que engloba a los grandes vasos, extendiéndose cranealmente desde los vasos renales hasta la bifurcación de las ilíacas; dicho conglomerado muestra una atenuación homogénea similar a la musculatura, a excepción de una zona en la vertiente anterolateral izquierda de bajo valor de atenuación sugestiva de componente quísticonecrótico (fig. 2) que muestra dimensiones de $4,6 \times 4,4 \mathrm{~cm}$, mostrando dicho conglomerado un diámetro craneocaudal de $9 \mathrm{~cm}$. No se observan adenopatías en el territorio de las ilíacas inguinales de tamaño significativo.

Se remite al paciente al servicio de Oncología de nuestro centro, sometiéndoselo a tres ciclos de bleomicina, etopósido y cisplatino, y a un cuarto de cisplatino y etopósido. Aproximadamente un año después se le realiza una linfadenectomía residual, con una anatomía patológica de necrosis y calcificación distrófica, intensa fibrosis y ausencia de tumor en todos los ganglios. Siendo seguido en el momento actual por ambas especialidades, en su última revisión (2/8/2008) no eleva marcadores.

Si bien la semiología inicial más frecuente es el aumento de tamaño indoloro, hasta un $10 \%$ de pacientes con tumores testiculares de células germinales (TTCG) presenta manifestaciones clínicas a distancia en el momento del diagnóstico, ya sea disnea por afectación pulmonar o mediastínica, dolor lumbar por enfermedad nodular retroperitoneal, etc ${ }^{1}$. En cualquiera de estas localizaciones, un inicio abrupto de la clínica, como en nuestro caso, sería debido a un crecimiento acelerado acompañado de necrosis o infarto tisular secundarios. Por otra parte, según las escasas series al respecto, la presentación como escroto agudo oscila entre el $0,01^{2}$ y el $10 \%{ }^{3}$. Pero es extremadamente raro su inicio como abdomen agudo. Haciendo una búsqueda vía PubMed, tan solo se citan dos casos de esta forma clínica de inicio ${ }^{9,10}$, y esta es la gran particularidad del caso que nos atañe. Se estima que en torno a un 1\% de los TTCG se presenta como una masa retroperitoneal asociada a un examen clínico de los testes sin alteraciones, lo cual dificulta un posible diagnóstico clínico en una sala de urgencias. En algunos pacientes se ha detectado un TTCG en testículos aparentemente normales a la exploración clínica de 5 meses a 14 años tras el tratamiento de un TTCG retroperitoneal ${ }^{4,5}$. Tanto es así que en una serie histórica de 29 TTCG retroperitoneales primarios evaluados por el Instituto Patológico de las FF. AA. de Norteamérica entre 1942-1946, 15 resultaron ser metástasis de tumores testiculares clínicamente indetectables y de ellos, en 8 se hallaron áreas de tumor quemado. Nuestro paciente sí presentaba una masa testicular palpable, pero la pieza tumoral contenía áreas de tumor quemado y tumor viable, el cual ya había metastatizado a pesar de comenzar la regresión en el punto de origen.

Los tumores de células germinales (TCG) en el retroperitoneo pueden tener un origen metastásico, más frecuente, o primario (por migración de células germinales durante la embriogénesis), ya que aproximadamente un 5\% de los TCG se origina fuera del testículo, en el espacio precoccígeo, retroperitoneal, mediastínico o en la pineal ${ }^{6}$. De todos los TCG en el peritoneo, el seminoma es el más frecuente, seguido por el carcinoma embrionario. La mayoría de pacientes con enfermedad nodular a este nivel refieren sintomatología lumbar baja e insidiosa, de ahí que sean manejados inicialmente como patología osteomuscular y referidos a trauma y a reumatología. Existen numerosas publicaciones de esta forma de presentación en la literatura médica ${ }^{7,8}$, no así de un inicio abdominal y agudo, como el caso que nos atañe.

Entre los varones de 15-35 años, la causa más frecuente de masas retroperitoneales son los TCG. Porque es muy raro un examen de bolsa escrotal sin alteraciones en estos pacientes, hay que tener en cuenta esta patología en nuestro diagnóstico diferencial y realizar una exploración completa en todo varón con masa abdominal palpable de este grupo etáreo ya que, aunque pueda parecer exagerada una exploración genital en estos pacientes, podemos llevarnos una desagradable sorpresa.

B I B L I O G R A F Í A

1. Richie JP. Neoplasms of the testis. En: Walsh PC, Retik AB, Vaughan ED, Wein AJ, editores. Campbell's Urology. Vol 3. 7 ed. Philadelphia: WB Saunders; 1998. p. 2411-52.

2. Cespedes RD, Caballero RL. Cryptic presentations of germ cell tumours. J Am Coll Surg. 1994;178:261-5. 
3. Presti JC, Herr HW. Genital tumors. En: Tanagho EA, McAninch JW, editors. Smith's General Urology, 14 ed. Connecticut: Appleton and Lange; 1998. p. 434-47.

4. Montague DK. Retroperitoneal germ cell tumours with no apparent testicular involvement. J Urol. 1975;113:505-8.

5. Munro AJ, Duncan W, Webb JN. Extragonadal presentations of germ cell tumours. Br J Urol. 1983;55:547-54.

6. Horwich A, Bajorin D. Testicular cancer: Presentation, assessment and prognosis. En: Raghavan D, Scher HI, Leibel SA, Lange $P$, editors. Principles and practice of genitourinary oncology. Philadelphia: Lippincott-Raven; 1997. p. 671-82.

7. Cole RP. Low back pain and testicular cancer. Br Med J. 1987;295:840-1.

8. Smith DB, Newlands ES, Rustin GJ, Begent RH, Bagshawe KD. Lumbar pain in stage1 testicular germ-cell tumours: a symptom preceding radiological abnormality. Br J Urol. 1989 Sep;64:302-4.

9. Delanian S, Breau JL, Morere JF, Israel L. Acute abdominal symptomatology disclosing a non-seminoma testicular tumor. Presse Med. 1987;16:1543.
10. Kantoff PW, Oliva E. Case Records of the Massachusetts General Hospital (Case 1-1000). N Engl J Med. 2000;342:1460.

M. Girón de Francisco ${ }^{\mathrm{a}, *}$, M. Álvarez Maestro ${ }^{\mathrm{b}}$, M.Á. Pérez-Utrilla Pérez ${ }^{c}$ y E. Collantes Bellido ${ }^{d}$

aServicio de Urología, Hospital Universitario La Paz, Madrid, España

${ }^{\mathrm{b}}$ Servicio de Urología, Hospital Infanta Sofía, Madrid, España

'Servicio de Urología, Hospital General de Ciudad Real, Ciudad Real, España

dServicio de Anatomía Patológica, Hospital del Río Hortega, Valladolid, España

*Autor para correspondencia.

Correo electrónico: manolo_giron@hotmail.com

(M. Girón de Francisco).

\section{A propósito de un cáncer de vejiga neuroendocrino mixto}

\section{An approach to a mix neuroendocrine bladder cancer}

\section{Sr. Director:}

El cáncer de vejiga neuroendocrino es una patología poco frecuente. Esta variedad de tumores es más frecuente en el pulmón y el tracto gastrointestinal. Dentro de los tumores neuroendocrinos de vejiga, el subtipo más frecuente es el de células pequeñas, descritos hasta el momento más de cien casos; menos común en estos tumores es el de células grandes, encontrando hasta la actualidad cuatro casos descritos en la literatura científica. Y en caso del paciente que nos ocupa, la celularidad mixta de carcinoma neuroendocrino de célula pequeña y carcinoma neuroendocrino de células grandes solo se ha descrito hasta el momento actual, según nuestro conocimiento, en un caso ${ }^{1}$.

Presentamos el caso de un varón de 71 años con antecedentes personales de hipertensión arterial, hernia de hiato, hipoacusia, fibrilación auricular paroxística y enfermedad pulmonar obstructiva crónica. Era ex fumador y agricultor con exposiciones frecuentes a pesticidas. Estaba en tratamiento con $\alpha$-bloqueantes por hiperplasia benigna de próstata.

En octubre de 2002 consultó por un episodio de hematuria macroscópica con coágulos, sin otra sintomatología acompañante, observando en cistoscopia una neoformación pediculada sólida, de color blanquecino y de $2,7 \mathrm{~cm}$ de diámetro mayor en la cara anterior de la vejiga. Un mes después se realizó resección transuretral de la vejiga cuyo informe anatomopatológico se informó como carcinoma urotelial grado 3 con infiltración de la capa muscular (pT2G3), sin imágenes de invasión vascular ni infiltración perineural. Los estudios posteriores de extensión (tomografía axial computarizada abdominopélvica y de tórax) resultaron negativos.
En diciembre de 2002 se realizó cistectomía parcial, ya que el paciente, por su patología respiratoria de base, no podía ser sometido a cistectomía radical. El postoperatorio concluyó sin incidencias que destacar.

En el informe anatomopatológico destacaba la infiltración de las capas musculares de la vecindad del borde quirúrgico lateral. Histológicamente correspondía a una neoplasia indiferenciada dispuesta en nidos sólidos en cuyo seno se identificaban frecuentes rosetas, abundantes figuras de mitosis y focos de necrosis, incluyendo dos poblaciones celulares entremezcladas entre sí (fig. 1), una de las cuales era de tamaño intermedio con escaso citoplasma y núcleos regulares de cromatina granular con

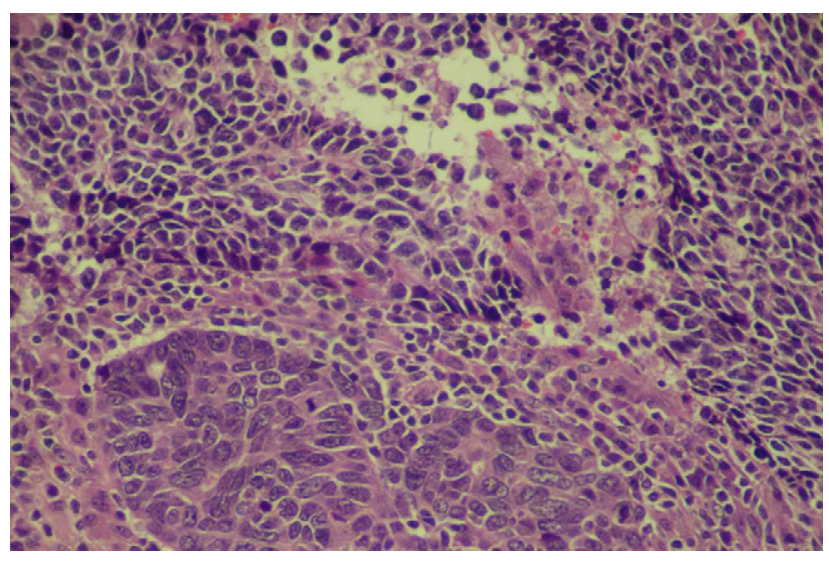

Figura 1 - Vista al microscopio de dos poblaciones celulares entremezcladas. 